\title{
Las cooperativas rurales: una oportunidad para repensar el rol del Estado frente a los impactos de la regulación de semillas en Colombia
}

(Rural cooperatives: an opportunity to rethink the role of the State in the face of seed regulation effects in Colombia)

\author{
Iván Vargas-Chaves ${ }^{1}$ \\ Universidad Militar Nueva Granada (Colombia) \\ Francisco Acevedo-Caicedo² \\ Universidad La Gran Colombia (Colombia) \\ Eduardo Salgado-Figueroa ${ }^{3}$ \\ Universidad Tecnológica de Bolívar (Colombia)
}

Sumario: Introducción. 1. Planteamiento de la problemática. 2. El mínimo vital de los campesinos y el rol del Estado: entre los derechos liberales y sociales. 3. Repensando el rol del Estado a través del cooperativismo. 4. Las cooperativas rurales como oportunidad ante los impactos de la prohibición de resiembra de semillas no certificadas. 5. Conclusiones. 6. Referencias bibliográficas.

Summary: Introduction. 1. Approach to the problem. 2. The vital minimum of the peasants and the role of the State: between liberal and social rights. 3. Rethinking the role of the State through cooperativism. 4. Rural cooperatives as an opportunity to face the impacts of the prohibition of replanting non-certified seeds. 5. Conclusions. 6. Bibliographic references

1 Doctor en Derecho; Doctor en Derecho Supranacional e Interno. Profesor de carrera de la Universidad Militar Nueva Granada. Contacto: ivan.vargas@unimilitar.edu. co; ivargas@outlook.com; ORCID: 0000-0001-6597-2335

2 Magíster en Derecho de la Empresa y de los Negocios. Profesor de carrera de la Universidad La Gran Colombia. Contacto: francisco.acevedo@ugc.edu.co ORCID: 00000003-0925-7753

3 Magíster en Derecho. Profesor de carrera de la Universidad Tecnológica de Bolívar (Cartagena de Indias, Colombia). Contacto: esalgado@utb.edu.co; ORCID: 0000-00019938-7994 
Resumen: El presente artículo analiza los diversos factores que inciden en la situación de vulnerabilidad en el que se encuentra el sector rural en Colombia, la cual se ha visto reforzada por el régimen de certificación de semillas que les prohíbe a los campesinos resembrar material parental no certificado. A través de una serie de reflexiones llevadas a cabo en el marco de un enfoque metodológico analítico-deductivo, los autores proponen un redimensionamiento del rol que debe tener el Estado para garantizar sus derechos e invitan, a manera de resultado, a considerar al cooperativismo como una solución a esta problemática, a través de las cooperativas rurales como un eje motor de la recuperación y la revitalización del campo.

Palabras clave: Cooperativas rurales; Cooperativismo; Derechos de los campesinos; Certificación de semillas; Obtenciones vegetales.

Abstract: This paper analyzes the causes that affect the rural sector in Colombia, making farmers vulnerable. The situation is made worse as a result of the seed certification regime that prohibits farmers from replanting non-certified parental material. The authors present some reflections from an analytical-deductive approach, with an invitation to rethink the role of the State, to guarantee their rights. As a result, the cooperativism is proposed as a solution to this problem, through rural cooperatives as a driving force for the recovery and revitalization of the countryside.

Keywords: Cooperativism; Peasant Rights; Plant varieties; Rural cooperatives; Seed certification; 


\section{Introducción}

Colombia hasta hace unas décadas era un país con una alta concentración de ciudadanos establecidos en zonas rurales, en su mayoría campesinos. Esto es algo que ha venido cambiando en la medida que el desplazamiento forzado, el acaparamiento de tierras o la alta monetización, entre otros fenómenos, han impactado el sector rural (Giraldo, 2015). Pese a ello con el nuevo régimen de certificación de semillas que trajo consigo el Tratado de Libre Comercio entre Colombia y Estados Unidos, se agravó aún más esta situación.

Desde el año 2010 los campesinos no pueden resembrar semillas que no sean certificadas por el Estado colombiano, que las puertas a las multinacionales obtentoras vegetales para introducir sus semillas modificadas genéticamente. Con este escenario, los papeles en el mercado se han invertido, y ahora son los campesinos quienes dependen de terceros para sacar adelante sus cosechas.

El presente artículo, busca poner de relieve el rol de las cooperativas rurales como una solución para hacer frente a la problemática antes mencionada. Se resaltan los beneficios que trae consigo el cooperativismo de la mano del Derecho cooperativo, para organizar a los campesinos con miras a afrontar conjuntamente y de una manera más coordinada el nuevo escenario resultante tras la prohibición.

Para ello, en primer lugar se procederá a plantear el escenario ya descrito. En el segundo y tercer apartado se cuestiona el lugar que ocupa el Estado como garante de los derechos de los campesinos, y se invita a repensar su papel, además de concebir al cooperativismo como un enfoque integral e integrador. Por último, se lleva a cabo un análisis sobre los beneficios que traerían las cooperativas rurales para afrontar la situación precaria que tienen los campesinos, en un mercado que les repliega obligándoles a abandonar su modo de vida.

La metodología escogida mantiene un enfoque analítico-deductivo, a partir de los postulados que se extraen de teóricos referentes en este ámbito. Como resultados se analizan y se comparan diversas perspectivas sobre estudios rurales, derechos de los campesinos y cooperativismo. En los apartados finales se sintetizan una serie de reflexiones que a juicio de los autores son relevantes para la línea argumentativa; además de proponer unos argumentos propios para enriquecer el debate de cara a futuras aproximaciones. 


\section{Planteamiento de la problemática}

El actual modelo de desarrollo rural basado en el acaparamiento, la producción, la transformación y la comercialización de productos agrícolas además de deteriorar el ambiente, ha afectado notablemente los intereses de los campesinos quienes hoy apenas participan -otros no logran hacerlo- en los procesos de transformación y generación de valor agregado a lo que ellos mismos cultivan (Brush, 2001; Carolan, 2008).

Este panorama se refuerza por políticas públicas y una normatividad que privilegia la producción agroindustrial y a estas grandes multinacionales (Archila y Betancurt, 2015). El mercado internacional también adquiere un rol protagónico, mientras que la demanda interna pasa a un segundo plano, al mismo tiempo que la soberanía alimentaria, el derecho a un trabajo y a una vida digna se ven comprometidos.

Colombia pasó de ser un país agrario basado en el trabajo de los campesinos - como lo fue hasta mediados del siglo pasado- a uno en el que la agroindustria es el principal y casi único motor de este sector. Así, mientras la decisiva influencia de la economía campesina quedó atrás, en el campo se han venido concentrando las grandes tensiones que han disparado el fenómeno del desplazamiento hacia las urbes (Perfetti, 2009).

«El modelo de desarrollo agrícola seguido en Colombia durante los últimos 55 años, ha creado las condiciones para que en el país no se logren mayores avances en materia de reducción tanto de la pobreza como de la inequidad en el campo colombiano.» (CRECE, 2006, p. 24)

Este fenómeno se ha acentuado más debido a la confluencia de otros factores igual de importantes, tales como la violencia armada, el narcotráfico que ha masificado la producción de cultivos de uso ilícito, el acaparamiento de tierras o una inequitativa distribución del ingreso rural generada en parte por el monto percibido por los intermediarios en la comercialización de los productos y el valor que recibe el campesino.

Sobre este último aspecto, señala Schejtman (1980), históricamente la capacidad de las unidades campesinas de enfrentar al mercado a precios «que a un eficiente productor empresarial lo llevarían muchas veces a incurrir en pérdidas hasta de sus costos corrientes» demuestra que existe una discriminación de parte del Estado en valorar recursos y productos de los campesinos versus el sector privado. 
En efecto, la cadena de valor de los productos de la cosecha es controlada por intermediarios -entre estas plantas de procesamientos, centrales de sacrificio y de abastos, frigoríficos o los distribuidores como lo son las grandes superficies y almacenes de cadenaque se terminan quedando con el mayor volumen de ganancias posible (Archila y Betancurt, 2015; Baquero-Melo, 2017). Por no dejar de mencionar la confluencia de otros fenómenos como el estancamiento del nuevo empleo en el campo, la falta de apoyo y estímulo a los campesinos, además de una y pobre política de formación de talento humano cualificado y de gasto público al sector rural (Bolaños, 2018).

No en vano el Estado colombiano está en mora de redefinir su política agraria de cara a enfrentar los desafíos que trae consigo la cuarta revolución industrial y la tecnificación de la producción agrícola.

Pero si hay un factor que ha resultado ser un detonante social, económico y que ha intensificado la pobreza, las desigualdades y la afectación del mínimo vital de los campesinos en Colombia, es el régimen de certificación de semillas implementado a través de la Resolución 970 de 2010 del Instituto Colombiano Agropecuario, por sus siglas ICA, que trajo como una de sus novedades la prohibición de resembrar semillas que no estuviesen certificadas por esta entidad.

Antes de esta norma el campesino contaba con dos opciones, siendo la primera de ellas la compra de la semilla o material parental en los dispensarios habilitados para tal fin. A través de la segunda opción, que es la resiembra, el campesino seleccionaba los mejores frutos de una cosecha y los utilizaba como semillas para el siguiente ciclo tras haber tomado como referencia el rendimiento del cultivo en el ciclo anterior. De esta manera elegía la semilla más vigorosa tras ventear el grano o tratar el material parental para la especie, en el caso de los bulbos, tubérculos u otros órganos de la variedad utilizados con fines de multiplicación (Álvarez, 2011).

«Reutilizar la semilla era una práctica común para más de 3.500.000 de familias campesinas en Colombia (...) Después de ventear la semilla, esta se airea para eliminar los restos de maleza o cualquier otro rastro que pueda tener, esto se hace manual, posteriormente las semillas se exponen al sol durante varios días para eliminar la humedad que pueda tener el grano (...) Esta es la etapa en la cual algunos campesinos separan las semillas para así, seleccionar cuales serán usadas en la próxima cosecha y el resto de semillas es guardado en sacos en un lugar seco para en un futuro ser intercambiado.» (Vargas-Chaves y Luna-Galván, 2017, p. 61) 
En este régimen a los campesinos no les está permitido resembrar semillas que no se encuentren certificadas salvo una excepción, y es que la resiembra se realice por una única vez en un terreno no mayor a un determinado número de hectáreas, y siempre que la semilla del ciclo anterior haya sido adquirida en un dispensario. A partir del siguiente ciclo - tras esa resiembra - el campesino deberá adquirir una vez más la semilla o material parental, y esperar un ciclo más para resembrarlo nuevamente por una única vez. Es lo que se conoce como la excepción del agricultor.

A manera de aclaración, es importante resaltar que, aunque la Resolución 970 de 2010 del ICA fue suspendida por orden del Gobierno tras negociar la terminación del Paro Nacional Agrario de 2013, luego fue derogada y reemplazada por la Resolución 3168 de 2015 del ICA. Esta nueva resolución no contempló cambios estructurales por lo que, en esencia, el régimen se mantiene.

En relación con las semillas certificadas, éstas son de capital extranjero y provienen de un mercado bajo el dominio de las multinacionales obtentoras vegetales, entre estas, Monsanto/Bayer, Dow, BASF, Dupont o Syngenta (Gomiero y Di Donato, 2017). Este fue un sector que participó de manera activa en las negociaciones del Tratado de Libre Comercio entre Estados Unidos y Colombia, donde se negoció este régimen para favorecer la entrada de semillas modificadas genéticamente y abrirse con el mercado obligando a todos los campesinos a adquirirlas (Mejía-Toro, 2014; Vargas-Chaves, Gómez-Rey \& Rodríguez, 2018).

Además, con la adquisición de semillas certificadas en dispensarios, los campesinos deben adquirir de manera simultánea los insumos para la cosecha, por ejemplo, abonos o pesticidas. Es lo que se denomina el argumento de la dependencia. Mientras mayor sea la dependencia de los campesinos en cuanto a bienes e insumos que deben adquirir para poder producir, tanto mayor será la «fuerza con que consideraciones de tipo mercantil intervengan en las decisiones sobre el qué y el cómo producir» en palabras del mismo Schejtman (1980).

Si los campesinos deben por sí asumir ya un costo no contemplado en su modelo tradicional de producción al tener que adquirir las semillas certificadas, sin duda éste aumentará con los insumos. El resultado será una escasa o nula participación en este proceso, además de bajas utilidades y los riesgos que estas semillas modificadas genéticamente traen a la biodiversidad y los cultivos adyacentes (Archila y Betancurt, 2015)

Así, pues, mientras en la balanza del mínimo vital de los campesinos se decanta el peso hacia los intereses económicos versus la soberanía alimentaria de millones de familias campesinas, el escenario 
resultante invita a repensar el rol que debe tener el Estado. Para Campos (2015), Glipo y Pascual (2005) es el inicio de la desestabilización de economías rurales como la nuestra, en la que los campesinos al no lograr producir a costos razonables, terminan abandonando este modo de vida y por consiguiente el campo.

\section{El mínimo vital de los campesinos y el rol del Estado: entre los derechos liberales y sociales}

La distinción entre derechos liberales y derechos sociales se sustenta en una visión de derecho subjetivo en el marco de las distintas categorías de derechos fundamentales. La doctrina ha sido generosa en aproximaciones tanto críticas como a favor (Peces Barba, 1999; Aldunate, 2008; Ruiz, 1994), logrando llegar a consensos que sitúan a los primeros como derechos «indiscutiblemente reconocidos» y a los segundos como «esencialmente controvertidos» (Arriagada Cáceres, 2015).

Pese a ello, en la práctica, insistir en mantener distinciones entre derechos fundamentales implica asumir que unos tienen más peso que otros. Esto se puede ver en el caso del derecho al mínimo vital. Un derecho cuyo reconocimiento se dio por vía jurisprudencial a través de la Sentencia T-426 de 1992 de la Corte Constitucional, y que contempla caracterizar en un único derecho todo un conjunto de intereses jurídicos tutelados en el marco del Estado Social de derecho, tales como la dignidad humana, la igualdad o la integridad personal.

Si se analiza este derecho en el contexto de derechos liberales, es posible encontrarse con que el Estado tendría el deber de abstenerse en aras de garantizar su pleno cumplimiento. En el caso de los campesinos, debería entonces permitirles autoabastecerse mediante la resiembra de semillas, de la misma manera como, en otros escenarios, tiene el deber de garantizar la libre circulación de los ciudadanos por las carreteras o dar todas las condiciones para que se ejerza el derecho al voto.

Por otra parte, si se sitúa el derecho al mínimo vital de los campesinos sobre las bases de los derechos sociales, se comprendería que el Estado tiene una obligación de prestación. Sería el caso de los subsidios dirigidos al campesinado colombiano, o las deducciones que en materia arancelaria se contemplan para la adquisición de maquinaria. Ello, de la misma manera en que - en otros escenarios - asume la carga prestacional de la educación pública o el régimen subsidiado de salud.

Nótese cómo en los dos casos el mínimo vital de los campesinos se sitúa en el escenario de los derechos liberales y en de los derechos sociales ¿Cómo es esto posible? ¿Acaso no son visiones que permiten 
distinguir el rol del Estado respecto a sus administrados? en este caso los campesinos.

Ciertamente hay una aproximación dogmática que logra dar respuesta a estos cuestionamientos de manera satisfactoria. Desde la concepción práctica y «terrenal» que Ife (2012) propone para los Derechos humanos, es posible rechazar cualquier distinción en tanto que ello no resuelve los problemas de fondo.

La distinción entre derechos liberales y sociales debe dejar a un lado cualquier consideración relacionada con la conducta que debe asumir el Estado: no debe ser una conducta pasiva para algunos derechos y una conducta activa para otros. Todos los derechos fundamentales tienen igual valor, y el Estado por activa o por pasiva debe garantizar su cumplimiento.

Volviendo al caso de los campesinos, al mantener este erróneo enfoque de los derechos liberales, se admite entonces una conducta pasiva que llevaría al Estado a permitir —o lo que es lo mismo, a acoplarse a la máxima de Laissez faire, laissez passer - que la agroindustria acapare los medios de producción alimentaria. Así, con la prohibición de resembrar semillas, el Estado permite el libre mercado en aras de garantizar una supuesta estabilidad y homogeneidad de las semillas certificadas aunque, como se reseñó, en el fondo cumpla con un compromiso establecido vía TLC con los Estados Unidos.

Como resultado, en la última década ha aumentado de manera drástica el desplazamiento de campesinos a las grandes ciudades (Naranjo, 2004), un fenómeno que no es otra cosa sino la consecuencia del abandono del campo por parte del Estado, quien actuó en contravía de los intereses de sus administrados. Ello, al permitir un monopolio injustificado y no acatar con su deber de garantizar el mínimo vital de los campesinos al permitirles alimentarse para subsistir por su propia cuenta.

Desde el otro enfoque conductual de derechos, propio de quienes propugnan por el deber prestacional del Estado sobre los derechos sociales - o lo que es lo mismo, de mantener una conducta activa - el derecho al mínimo vital se consumaría por medio de los subsidios que éste dispone para los campesinos desplazados a las grandes ciudades.

Son subsidios que tampoco aseguran el mínimo vital, pues las condiciones de vida son cada vez más complejas para un sector tan vulnerable. La inflación, el desempleo, la pobreza y la violencia, entre otros problemas no resueltos, dejan entrever que el Estado aún no cumple con el mandato impuesto por la Corte Constitucional en la citada sentencia.

Por lo anterior, se insiste en la necesidad de dejar a un lado este tipo de dicotomías doctrinales para repensar una vez más el lugar que 
ocupan los derechos humanos "en el terreno», un concepto que se relaciona principalmente con la penetración de la gobernabilidad en todos los ámbitos de la relación Estado y administrados.

Sin duda, al igual que Geiger y Pécoud (2010), coincidimos en que es viable afirmar que los derechos humanos tienen un papel protagónico y, al mismo tiempo, ambivalente y adaptable a las necesidades y expectativas de la sociedad en la que rija el contrato social.

\section{Repensando el rol del Estado a través del cooperativismo}

Ante un panorama de un incumplimiento notorio de ese deber que tiene el Estado de garantizar el mínimo vital a los campesinos, resulta válido preguntarse ¿Qué otras estrategias puede promover éste en aras de cumplir con su mandato constitucional? Cracogna (2019) invita a repensar el rol del Estado en pro del bienestar social y la sostenibilidad de las comunidades a través de una dignificación del trabajo y de su empoderamiento.

Esta visión toma a las cooperativas como el eje motor de políticas públicas, basado en su autonomía e independencia; políticas que por demás pueden llegar a articular eficientemente los esfuerzos de todos los integrantes de una comunidad. El cooperativismo, más allá de ser una pieza dentro del engranaje de la economía centralmente planificada, es un engranaje de las comunidades en sí.

Ahora bien, es un hecho que la prohibición de resiembra —además de los factores reseñados en el primer apartado de este artículo- pone en una situación de desventaja a las pequeñas y medianas comunidades campesinas en el mercado frente a sus competidores provenientes del sector agroindustrial (Perelmuter, 2013; Ceceña, 2001). Los productos de sus cosechas no pueden competir en igualdad de condiciones, y el derecho a su mínimo vital se ve comprometido. Con el fortalecimiento de las cooperativas rurales, el Estado podría llegar a equilibrar la balanza, y esto no es algo nuevo.

El conjunto normativo que recoge las bases del cooperativismo en lo que se denomina Derecho Cooperativo, tiene sus orígenes en el Reino Unido a mediados del siglo XIX. La Ley de Cooperativas de 1852 se convirtió en el primer antecedente de un sistema de normas que impulsan la defensa y salvaguarda, tanto de intereses jurídicos tutelados como de valores fundamentales en nuestra sociedad (Yorg \& RamírezZarza, 2018). Todo esto, en procura de la justicia social para afianzar la coexistencia entre todos los individuos.

Sobre las bases del cooperativismo, es pertinente traer a colación la Declaración Mundial sobre Cooperativismo de Trabajo Asociado de 2005. 
Allí se establece un norte que para el desarrollo del presente artículo puede ser esclarecedor: los hombres debemos buscar permanentemente la superación cualitativa de cualquier forma de organizar el trabajo, en búsqueda de lograr unas mejores, justas y más dignas relaciones laborales.

En relación al modelo asociativo «donde el trabajo y la gestión se realizan conjuntamente, sin las limitaciones propias del trabajo individual ni exclusivamente bajo las reglas del trabajo asalariado dependiente» se conciben a las cooperativas como la modalidad que «más desarrollo e importancia alcanza actualmente en el mundo y está estructurado en base a los principios, valores y métodos de operación que tienen las cooperativas a nivel universal» (Declaración Mundial sobre Cooperativismo de Trabajo Asociado de 2005, art. 3)

Este enfoque está consagrado en la Recomendación 193/2002 de la Organización Internacional del Trabajo sobre la Promoción de las Cooperativas y en la Declaración de Manchester sobre Identidad Cooperativa de 1995 donde se instituye el fin supremo que tienen las cooperativas: trabajar en pro del desarrollo sostenible de su comunidad basado en los valores de ayuda mutua, solidaridad, participación democrática y solidaria, responsabilidad, equidad e igualdad.

En relación con la naturaleza jurídica de esta importante figura, ésta suele enfocarse varios ángulos, de los cuales destacan tres visiones. La primera, concibe a las cooperativas como asociaciones, la segunda de ellas las concibe como sociedades y la tercera las enmarca como una categoría autónoma (Hernández Aguilar, 2015). Esta clasificación resulta bastante ilustrativa para evidenciar qué tan avanzada se encuentra esta disciplina jurídica.

Para los efectos del hilo argumentativo del artículo, y más allá de encajar en una de estas visiones, es importante considerar que su origen se da como organización y organismo constituido por un grupo representativo de individuos quienes, de manera voluntaria, deciden aportar bienes o trabajo en procura del cumplimiento de unos fines comunes.

En el caso de las cooperativas rurales estos fines comunes contemplan el fomento de su actividad, la soberanía alimentaria, el acceso a nuevos mercados y la salvaguarda de los intereses de los campesinos en el mercado en el que participan.

Si los Estados comprenden que, al incentivar la asociación de campesinos en cooperativas, éstos contarán con una plataforma para llegar a consensos sobre la mejor forma de actuar coordinadamente para hacer valer sus derechos, en especial el derecho a un mínimo vital, así como para autorregularse y buscar vías para una distribución equitativa de los beneficios, pero, sobre todo, para hacer frente a un sector que década tras década crece: la agroindustria. 
Al hablar de un redimensionamiento del rol del Estado a partir de las cooperativas rurales, y en relación con la situación que aqueja a cientos de miles de campesinos en Colombia, lo que se busca es superar la dicotomía entre conducta activa o pasiva según se mire al mínimo vital como un derecho liberal o social. Es una ruta a ser tomada por las mismas autoridades públicas, quienes deben tener presente que el cooperativismo es un camino idóneo para solucionar los diversos problemas que trae consigo la desigualdad y que aquejan no solo al campo, sino a la sociedad en general. En palabras de Hagen Henrÿ:

«No se puede creer que un funcionario de autoridad fiscal va a aplicar un régimen específico a las cooperativas si en su preparación nunca ha oído el término Cooperativa (...) a futuro, el cooperativismo traerá grandes soluciones al quehacer social» (Henrÿ, 2016)

Asimismo, el Estado debe reconsiderar su visión limitada de cooperativas como sociedades mercantiles, en pro de generar las condiciones para un verdadero desarrollo sostenible, tal como lo propone la Alianza Cooperativa Internacional (Pacheco Almaraz et al., 2019). A su vez, se garantizará el mínimo vital en consonancia con la Declaración de Estocolmo de 1972, que propugna por el disfrute de unas condiciones de vida adecuadas en un medio que permita al individuo llevar una vida digna y gozar de bienestar.

\section{Las cooperativas rurales como oportunidad ante los impactos de la prohibición de resiembra de semillas no certificadas}

Como se mencionó en el primer apartado del artículo, con la prohibición de resiembra de semillas no certificadas los campesinos deben asumir costos adicionales, entre estos el tener que adquirir en dispensarios las semillas que pasaron por un proceso de certificación, así como de forma simultánea adquirir los pesticidas y abonos que sólo sirven para las cosechas provenientes de dichas semillas. Así, los campesinos se ven limitados en sus opciones, y como consecuencia de esta dinámica sus ingresos disminuyen notablemente.

A ello se suma el problema de adaptabilidad de las semillas certificadas a los terrenos de siembra, pues no en todos los casos logran producir cosechas en las condiciones de estabilidad esperadas (Perelmuter, 2017). Los campesinos pueden llegar a perder cosechas enteras, sin que por su propia cuenta puedan ser capaces de afrontar las pérdidas. Lo lograrían con suficiencia en el marco de un modelo de economía so- 
lidaria donde una cooperativa rural tendría mayor robustez para asumir las pérdidas.

Y es que los procesos de propagación, multiplicación o reproducción de las especies nativas -es decir las semillas no certificadas- se han dado a lo largo de décadas o siglos en un terreno, lo cual garantizaba que estas semillas se habían ya adaptado al mismo (Rees, 2008). Con las nuevas semillas certificadas, este proceso es inexistente pues el material parental se creó en un laboratorio (Elmore et al., 2001). De hecho, en su gran mayoría, son obtenciones vegetales no convencionales modificadas genéticamente, o lo que es lo mismo semillas transgénicas (CITA).

Así, pues, con un modelo de economía solidaria los campesinos tendrían posibilidades de organizarse a través de cooperativas rurales para hacer frente a la financiación de las cosechas, capacitarse para el manejo de las nuevas semillas, compartir experiencias y, en últimas repartir cargas de pérdidas y ganancias. De esta manera el Estado dotaría a los campesinos de una herramienta poderosa a través de la cual se aseguraría el mínimo vital de los campesinos.

Es preciso señalar en este punto que el cooperativismo no es algo nuevo en Colombia. Sus orígenes datan del inicio de la década de los treinta como un modelo impulsado por la Iglesia católica en aras de impulsar el desarrollo rural, social y la economía provincial (Dávila, 1996). En ámbito latinoamericano, a partir de los sesenta es posible observar un aumento importante de la actividad de la economía social y solidaria, que ya para entonces se proyectaba como un sector desmarcado de toda lógica mercantilista (García-Müller y Álvarez, 2012).

Y aunque en estas primeras etapas a ninguna de las cooperativas se le habría ocurrido acudir al Estado para sostenerse, con el tiempo fue surgiendo lo que Münkner (2005) denominó 'una inédita relación entre Estado y cooperativas'. Con este importante antecedente nace una relación de colaboración que pone a las cooperativas como organizaciones que coadyuvan al Estado a lograr los objetivos de progreso económico y social (Cracogna, 2019).

Ese rol clave que debe asumir el Estado con los campesinos que se han visto afectados por la dinámica antes descrita, debe partir por legislar y regular los modelos asociativos para que puedan crearse nuevos -o mejorarse los actuales- modelos para prestar servicios financieros y complementarios; para mantener en estructuras sólidas el capital económico y social acumulado; y para fomentar la transparencia en la gestión de los recursos. De este modo, para autores como Dávila (1996), las cooperativas se convertirán en verdaderos motores del desarrollo local y regional. 
Desde la óptica del Derecho cooperativo comparado, la experiencia cubana nos muestra que un modelo cooperativista impulsado desde el mismo Estado, permite formar cooperativas «a partir de medios de producción del patrimonio estatal, tales como inmuebles y otros, que se decida gestionar de forma cooperativa y para ello puedan cederse estos, por medio del arrendamiento, usufructo u otras formas legales que no impliquen la transmisión de la propiedad». (República de Cuba, Decreto-Ley 305 de 2012, art. 6)

Si a lo anterior le añadimos una normatividad que promueva el acceso a créditos, reduzca o elimine exenciones arancelarias, deducciones tributarias o impulse medidas para acceder a nuevos mercados, se podrá asegurar la sostenibilidad de las cooperativas y un éxito en la relación entre el Estado y las cooperativas rurales. Estas cooperativas también podrían verse beneficiadas por una regulación que proyecte el cooperativismo de servicios de carácter periférico, un modelo que, según Larranñaga (1993), además de permitir el desarrollo de una sociedad provincial rural, coadyuva al sostenimiento de la economía campesina.

Por último, el Derecho cooperativo juega también un papel crucial en la promoción de la cooperación, la justicia social y la solidaridad como valores superiores de una escala axiológica (Yorg \& Ramírez-Zarza, 2018). Valores que sean capaces de trasformar el actual escenario por un orden solidario y cooperativo, dejando a través el orden económico-social individualista y competitivo promovido en el pasado por el Estado a favor de las grandes multinacionales obtentoras vegetales.

En definitiva, al darle a las cooperativas el lugar que merecen como ejes motores que permiten superar cualquier rezago propio de un régimen de certificación de semillas que no logró dimensionar sus efectos en la economía campesina, el Estado propenderá no sólo por el mejoramiento de la calidad de vida de los campesinos, sino que garantizará su mínimo vital y les mantendrá como un sector muy importante de nuestra sociedad.

\section{Conclusiones}

Son varios factores los que inciden en la problemática de pobreza en el campo colombiano y desplazamiento de los campesinos hacia las grandes ciudades. En los últimos años, el nuevo régimen de certificación de semillas impuesto por el Gobierno tras negociar vía TLC con los Estados Unidos la prohibición de resembrar aquellas que no 
estuviesen certificadas por el ICA, supuso un detonante que agravó aún más la situación.

En la práctica, para que un campesino pueda llevar a cabo esta práctica ancestral que consiste en tomar la mejor parte de su cosecha, y reutilizarla como semilla para una próxima siembra, debe dirigirse hoy en día a un dispensario y adquirir semillas que previamente hayan sido certificadas. Adicional a lo anterior, con el pago de éstas debe además asumir valor de los insumos que sólo sirven para dichas semillas.

Así, los campesinos se ven absorbidos por un mercado dominado por las multinacionales obtentoras vegetales, el cual les sitúa en un escenario de vulnerabilidad y afectación de su derecho a un mínimo vital. Ante esta situación, el Estado debe repensar su rol, pues los actuales enfoques de intervención para salvaguardar éste y otros derechos que conexamente se vulneran, no solucionan con suficiencia esta problemática. Se necesita un enfoque que empodere a los campesinos para que puedan actuar de manera coordinada.

Aquí es donde surge el Derecho cooperativo, una disciplina que está diseñada con el fin de dotar a la sociedad de herramientas para organizarse y actuar coordinadamente, ello en el marco de la economía social y en pro de una justicia social. En el presente artículo se invita a considerar el cooperativismo como una solución a tener muy en cuenta para empoderar a las comunidades campesinas, quienes durante siglos han sido el pilar de la economía en Colombia.

Con las cooperativas rurales no sólo se logra integrar a todos los campesinos productores de una comunidad para que actúen de manera coordinada, sino además se promueve un mejoramiento de sus condiciones de vida, además, de prescindir de intermediarios y por ende eliminar la dependencia hacia terceros.

El cooperativismo implica para estos efectos compartir responsabilidades, ganancias y pérdidas, así como acceder en igualdad de condiciones a los recursos técnicos y formación especializada. Implica también que los campesinos podrán estar mejor informados sobre esas 'nuevas' semillas que ahora deben utilizar; anticipándose a los riesgos y eventuales pérdidas de la cosecha. Por último, implica que podrán redistribuir los excedentes entre todos los integrantes, así como negociar en un único bloque con terceros manteniendo una mejor posición y, en definitiva, implica una incidencia activa en el mercado para recuperar su cuota de participación.

Sin duda el Derecho cooperativo como el brazo que el cooperativismo extiende para regular sus relaciones con el Estado, es lo que estimulará el desarrollo sostenible de las comunidades campesinas, garantizando un trabajo digno y evitando la exclusión social. En los términos 
de la Declaración Mundial sobre Cooperativismo de Trabajo Asociado de 2005, es una solución a los problemas de exclusión social que aquejan a nuestra sociedad, y un modelo que apunta por una relación laboral más avanzada, digna y justa de democratización y distribución de la riqueza.

El cooperativismo es, pues, lo que le permitirá a las comunidades campesinas hacer frente a los impactos relacionados con la dependencia y los altos costos. Con todo, no se concluye en el artículo que sea la solución definitiva, pero sí es una solución a tener muy presente, y que el Estado deberá considerar. Solo así podría retornarle al campo su dignidad; una dignidad que ha venido perdiendo a lo largo del tiempo.

\section{Referencias bibliográficas}

ALIANZA COOPERATIVA INTERNACIONAL, 1995. Declaración de Manchester sobre Identidad Cooperativa, 1995.

ALIANZA COOPERATIVA INTERNACIONAL, 2005. Declaración Mundial sobre Cooperativismo de Trabajo Asociado.

ÁLVAREZ, Martha. 2011. Multiplicación de plantas: Una guía esencial para conocer los distintos tipos de multiplicación y su correcta aplicación en el inicio de un cultivo. Buenos Aires: Editorial Albatros.

ARCHILA, Aleida y John BETANCURT. 2015. "La Economía campesina y solidaria: Una ruta para la Paz de Colombia». Atas CIAIQ2015, 3: 204-207. Desde https://proceedings.ciaiq.org/index.php/ciaiq2015/article/view/334

BAQUERO-MELO, Jairo. 2017. «Vulnerabilidad socioecológica y socioeconómica en cadenas de valor agrícola. El caso de la producción del plátano en Colombia». Revista Latinoamericana de Estudios Rurales, 2(3): 96-128. Desde http:// www.ceil-conicet.gov.ar/ojs/index.php/revistaalasru/article/view/198/114

BOLAÑOS, José Víctor. 2018. Problema agrario y lucha armada en Colombia: El caso de las FARC-EP. Ciudad de México: Universidad Nacional Autónoma de México.

BRUSH, Stephen. 2001. "Genetically modified organisms in peasant farming: social impact and equity». Indiana Journal of Global Legal Studies, 9(1): 135-162. Desde http://www.repository.law.indiana.edu/ijgls/vol9/iss1/8

CAMPOS, Carolina. 2015. Empoderamiento campesino y soberanía alimentaria en Colombia: la defensa de las semillas y los mercados campesinos. Leiden: Universidad de Leiden.

CAROLAN, Michael. 2008. "The multidimensionality of environmental problems: The GMO controversy and the limits of scientific materialism». Environmental Values, 17(1): 67-82. doi: https://doi. org/10.3197/096327108X271950

CECEÑA, Ana. 2001. "La territorialidad de la dominación: Estados Unidos y América Latina». Revista Chiapas, 12: 7-30. Desde https://chiapas.iiec. unam.mx/No12-PDF/ch12cecena.pdf 
CONFERENCIA DE LAS NACIONES UNIDAS SOBRE EL MEDIO HUMANO, 1972. Declaración de Estocolmo de 1972 sobre el Medio Humano.

CRACOGNA, Dante. 2019. «El principio de autonomía e independencia en la declaración sobre la identidad cooperativa». Boletín de la Asociación Internacional de Derecho Cooperativo, 55: 19-34. doi: http://dx.doi. org/10.18543/baidc-55-2019pp19-34

CRECE. 2006. Pobreza Rural: Diagnóstico y Evaluación de las Políticas Nacionales. Manizales: MIMEO.

DÁVILA, Ricardo. 1996. "Las cooperativas rurales y el desarrollo regional: el caso de las provincias del sur de Santander, Colombia». Cuadernos de Desarrollo Rural, 37: 47-62. Desde: https://revistas.javeriana.edu.co/index. php/desarrolloRural/article/view/3300

ELMORE, Roger, Fred W. ROETH, Lenis A. NELSON, Charles A. SHAPIRO, Robert N. KLEIN, Stevan Z. KNEZEVIC y Alex MARTIN. 2001. "Glyphosate-resistant soybean cultivar yields compared with sister lines». Agronomy Journal, 93(2): 408-412. doi: https://doi.org/10.2134/agronj2001.932408x

ESTEBAN SALVADOR, María Luisa, PÉREZ SANZ, Francisco Javier y GARGALLO CASTEL, Ana. 2018. "Áreas rurales y cooperativas: iniciativas de mujeres para el desarrollo». REVESCO, Revista de Estudios Cooperativos, 127: 116138. doi: http://dx.doi.org/10.5209/REVE.58397.

GARCÍA-MÜLLER, Alberto. 2012. "Cómo determinar qué entidades forman parte de la economía social y solidaria». Unisangil Empresarial, 5(1): 3946. Desde: http://publicaciones.unisangil.edu.co/index.php/revista-unisangil-Empresarial/article/download/22/27

GIRALDO, Omar. 2015. "Agroextractivismo y acaparamiento de tierras en América Latina: una lectura desde la ecología política». Revista Mexicana de Sociología, 77(4), 637-662. Desde: http://www.scielo.org.mx/scielo. php?pid=S0188-25032015000400637\&script=sci_abstract

GLIPO, Arze y Francisco PASCUAL. 2005. «Food sovereignity framework: concept and historic context» Nyleni, Diciembre de 2005: 1-23. Recuperado de: http://www.nyeleni.org/IMG/pdf/FoodSovereignityFramework.pdf

GOMIERO, Tiziano y Monica DI DONATO. 2017. "Megafusiones en el sistema agroalimentario: el caso de Bayer-Monsanto. ¿Qué riesgos hay en Europa?». Papeles de Relaciones Ecosociales y Cambio Global, 139: 39-53. Desde: https://www.fuhem.es/papeles_articulo/megafusiones-en-el-sistema-agroalimentario-el-caso-de-bayer-monsanto-que-riesgos-hay-en-europa/

HENRŸ, Hagen. 2016. «Conferencia sobre tendencias del derecho cooperativo y solidario» Universidad Cooperativa de Colombia, Bogotá D.C., 16 de febrero de 2016.

HERNÁNDEZ AGUILAR, Orisel. 2015. «Algunas reflexiones en torno a la dimensión jurídico-formal del proceso de constitución de cooperativas no agropecuarias en Cuba a partir del análisis del caso del municipio Pinar del Río». Boletín de la Asociación Internacional de Derecho Cooperativo, 49: 279-306. doi: http://dx.doi.org/10.18543/baidc-49-2015pp279-306 
HERNÁNDEZ SALAZAR, Giovanni Andrés y OLAYA PARDO, Ana María. 2018. «El marco legislativo y su efecto sobre el crecimiento del sector cooperativo en Colombia (1933-2014)». REVESCO, Revista de Estudios Cooperativos, 127: 139-158. doi: http://dx.doi.org/10.5209/REVE.58398.

INSTITUTO COLOMBIANO AGROPECUARIO, 2010. Resolución 970/2010.

INSTITUTO COLOMBIANO AGROPECUARIO, 2015. Resolución 3168/2015.

LARRAÑAGA, Jesús. 1993. "Las claves de la experiencia de Mondragón. Enfoque del futuro.» Jornadas sobre Cooperativismo, Cali, Colombia, 4 de junio de 1993.

MÜNKNER, Hans-H. 2005. 100 Years Co-operative Credit Societies Act India, 1904. Nueva Delhi: ICA Regional Office for Asia and the Pacific.

NARANJO, Gloria. 2004. «Ciudadanía y desplazamiento forzado en Colombia: una relación conflictiva interpretada desde la teoría del reconocimiento». Estudios Políticos, 25: 137-160. Desde: https://dialnet.unirioja.es/descarga/ articulo/5263737.pdf

ORGANIZACIÓN INTERNACIONAL DEL TRABAJO, 2002. Recomendación 193/2002 sobre la Promoción de Cooperativas.

PACHECO ALMARAZ, Victoria, María Isabel PALACIOS RANGEL, Fernando CERVANTES ESCOTO, Jorge OCAMPO LEDESMA y Jorge Aguilar Ávila. 2019. «La asociación cooperativa como factor de sostenibilidad del sistema cafetalero en comunidades marginadas». REVESCO. Revista de Estudios Cooperativos, 131: 125-150. doi: https://doi.org/10.5209/REVE.63563

PARDO MARTíNEZ, Luz Patricia y HUERTAS DE MORA, María Victoria. 2017. «Modelos influyentes en las cooperativas de ahorro y crédito en Colombia». REVESCO. Revista de Estudios Cooperativos, 125: 109-133. doi: http://dx.doi.org/10.5209/REVE.58134.

PERELMUTER, Tamara. 2017. El rol de la propiedad intelectual en los actuales procesos de cercamientos. El caso de las semillas en la Argentina (19732015). Buenos Aires: Universidad de Buenos Aires.

PERELMUTER, Tamara. 2018. «Apropiación de semillas: soberanía alimentaria y tecnológica en riesgo». Ciencia, Tecnología y Política, 1(1): 1-9. doi: https://doi.org/10.24215/26183188e008

PERFETTI, Juan José. 2009. «Crisis y pobreza rural en América Latina: el caso de Colombia». Rimisp Latin American Center for Rural Development Working papers, 43: 1-31. Desde: https://rimisp.org/wp-content/files_ mf/137210305043_CrisispobrezaruralColombia_Perfetti_2009.pdf

REES, Andy. 2008. Alimentos modificados genéticamente: una guía breve para las personas confundidas. Barcelona: Intermón Oxfam Editorial.

SCHEJTMAN, Alexander. 1980. «Economía campesina: lógica interna, articulación y persistencia». Revista de la CEPAL, 11: 121-140. Desde: https://repositorio.cepal.org/handle/11362/11934

SOUSA SILVA, Lindomar De Jesus de, COSTA PINHEIRO, José Olenilson, MORAIS DOS SANTOS, Endrio, COSTA, Jemima Ismael da y MENEGHETTI, Gilmar Antonio. 2019. "O cooperativismo como instrumento para a autonomia de comunidades rurais da Amazônia: a experiência dos agricultores extrativistas do municipio de Lábrea, AM». Boletín de la Asociación 
Internacional de Derecho Cooperativo, 55: 199-226. doi: http://dx.doi. org/10.18543/baidc-55-2019pp199-226.

VARGAS-CHAVES, Iván y Mauricio LUNA-GALVÁN. 2017. «Tres enfoques sobre las implicaciones de la prohibición de resiembra de semillas no certificadas en Colombia. En Memorias del Simposio de Investigación. Universidad Tecnológica de Colombia, Cartagena de Indias. Desde: https:// investigaciones.utb.edu.co/sites/investigaciones.unitecnologica.edu.co/files/descargas/memorias_invisible_0.pdf\#page $=58$

VARGAS-CHAVES, Iván, Andrés GÓMEZ-REY y Gloria Amparo RODRíGUEZ. 2018. "La invocabilidad de la acción de cumplimiento frente a los compromisos suscritos en el Paro Nacional Agrario de 2013: un análisis desde la regulación de las semillas certificadas». Jurídicas, 16(1): 28-45. doi: https:// doi.org/10.17151/jurid.2018.15.1.3

VARGAS PRIETO, Amanda y CASTAÑEDA GUZMÁN, Diana Carolina. 2019. «Efecto de las cooperativas exportadoras de café en el crecimiento de la economía solidaria en Colombia». REVESCO, Revista de Estudios Cooperativos, 130: 213-234. doi: http://dx.doi.org/10.5209/REVE.62810.

YORG, José Alberto y Ana María RAMÍREZ-ZARZA. 2018. «Interrelación entre el derecho laboral, derecho de incidencia colectiva y el derecho cooperativo. Estudio de caso». Boletín de la Asociación Internacional de Derecho Cooperativo, 53: 275-288. doi: http://dx.doi.org/10.18543/baidc53-2018pp275-288.

YORG, José Alberto y Ana María RAMÍREZ-ZARZA. 2018. «El derecho cooperativo y el docente cooperativo». Boletín de la Asociación Internacional de Derecho Cooperativo, 53: 169-180. doi: http://dx.doi.org/10.18543/baidc56-2020pp169-180. 


\section{Derechos de autor}

El Boletín de la Asociación Internacional de Derecho Cooperativo es una revista de acceso abierto lo que significa que es de libre acceso en su integridad inmediatamente después de la publicación de cada número. Se permite su lectura, la búsqueda, descarga, distribución y reutilización legal en cualquier tipo de soporte sólo para fines no comerciales y según lo previsto por la ley; sin la previa autorización de la Editorial (Universidad de Deusto) o el autor, siempre que la obra original sea debidamente citada (número, año, páginas y DOI si procede) y cualquier cambio en el original esté claramente indicado.

\section{Copyright}

The International Association of Cooperative Law Journal is an Open Access journal which means that it is free for full and immediate access, reading, search, download, distribution, and lawful reuse in any medium only for non-commercial purposes, without prior permission from the Publisher or the author; provided the original work is properly cited and any changes to the original are clearly indicated. 